\title{
Building knowledge development and exchange capacity in Canada: lessons from Youth Excel
}

\author{
B. Riley, PhD; K. Wong, MSc; S. Manske, EdD
}

This article has been peer reviewed.

\begin{abstract}
Introduction: Youth Excel was a 3-year pan-Canadian initiative to advance youth health through improving knowledge development and exchange (KDE) capacity. KDE capacity refers to an improvement cycle linking evidence and action. Capacities include local surveillance of youth behaviours; knowledge exchange; skills, resources and a supportive environment to use knowledge; and evaluation.
\end{abstract}

Methods: Interviews were conducted with Youth Excel members, including 7 provincial teams and 2 national organizations. Interviews explored participant experiences with building KDE capacity.

Results: Local surveillance systems were considered the backbone to KDE capacity, strengthened by co-ordinating surveys within and across jurisdictions and using common indicators and measures. The most effective knowledge exchange included tailored products and opportunities for dialogue and action planning. Evaluation is the least developed KDE component. Building KDE capacity requires frequent dialogue, mutually beneficial partnerships and trust. It also requires attention to language, vision, strategic leadership and funding.

Conclusions: Youth Excel reinforces the need for a KDE system to improve youth health that will require new perspectives and sustained commitment from individual champions and relevant organizations.

Keywords: knowledge development and exchange, capacity building, youth health, evidence to action, evidence-informed public health, local surveillance

\section{Introduction}

The capacity to generate and use relevant and high quality evidence is fundamental to public health. Although described in different ways, core functions of public health include assessment of health patterns and trends as well as developing, implementing and evaluating health programs and services in partnership with relevant collaborators. ${ }^{1,2}$ The limited capacity to perform these functions has been well-documented in many jurisdictions, as have calls to strengthen public health capacity. ${ }^{3-6}$
In response to these calls, a pan-Canadian team established Youth Excel, a 3-year initiative funded by the Canadian Partnership Against Cancer's Coalitions Linking Action and Science for Prevention (CLASP). ${ }^{7}$ The goal of Youth Excel was to strengthen the capacities for generating and using evidence-referred to as knowledge development and exchange (KDE) - to advance the health of Canadian youth aged 10 to 18 years. KDE involves improving the cycle linking evidence and action, including local surveillance of youth behaviours; fostering the skills and resources and the supportive environment to use and exchange knowledge; and evaluation (described in more detail below).

An internal, mixed methods evaluation of Youth Excel included a qualitative study to determine the lessons learned about building KDE capacity. This paper reports the results of the qualitative study.

\section{Research setting: Youth Excel}

Promoting population-level prevention and health with a particular focus on tobaccofree living as well as physical activity and healthy eating is the stated priority of government and non-governmental organizations in Canada, ${ }^{8}$ the United States ${ }^{9}$ and worldwide. ${ }^{10}$ Youth Excel (Youth Health Collaborative: 'Excelerating' EVIDENCE-informed ACTION) addressed these priorities among youth aged 10 through 18 years of age. Like other CLASPs, the aim of Youth Excel was to accelerate the dissemination and implementation of evidence-informed policy and practice through collaborating across jurisdictions and across research, policy and practice sectors. Youth Excel focused on the foundational capacities that enable evidence-informed decisions and actions. As the origins and design of Youth Excel are described in detail elsewhere, ${ }^{11}$ only a brief description follows.

Youth Excel was begun by a group of people who had collaborated on other projects and who shared a common goal of ensuring that youth health priorities, programs and policies in Canada are evidence-informed. Teams from 7 provinces (BC, $\mathrm{AB}, \mathrm{MB}, \mathrm{ON}, \mathrm{NB}, \mathrm{NL}, \mathrm{PE})$ and 2 national organizations-the Pan-Canadian 
Joint Consortium for School Health (JCSH) and the Propel Centre for Population Health Impact (Propel)-envisioned a future in which all federal, provincial and territorial jurisdictions in Canada would routinely convene leaders in policy, practice and research to (1) jointly set priorities for action, identifying highest needs and determining what interventions are the most promising; (2) act on priorities; (3) learn from actions and evaluate promising approaches and (4) continuously improve policies and programs that enhance youth health. This vision for Youth Excel represents a quality improvement cycle that links evidence and action. Youth Excel refers to this cycle, which includes local surveillance of youth behaviours, knowledge exchange, the skills and conditions to use the evidence and the evaluation, as KDE capacity (Figure 1).

To strengthen KDE capacity, Youth Excel capitalized on existing partnerships and built new ones. Members worked in research, policy and practice and the health and education sectors, and had up to 16 years of project-specific collaborations before creating Youth Excel. In addition, the stage of development and initiatives related to KDE capacity varied substantially across the 7 participating provincial teams (see Table 1). This variability provided a "natural experiment" that guided the aims and activities of Youth Excel.

Youth Excel members developed 5 main activities to strengthen KDE capacity. The first capitalized on the more advanced
KDE developments in some provinces. Indepth, comparative case studies of KDE capacity were conducted in 4 provinces (AB, MB, NB, PE). The second main activity was establishing national forums that convened people from policy, practice and research to learn, share and uncover ways to build KDE capacity. For example, one national forum focused on sharing lessons from the provincial case studies and providing an opportunity for action planning within provinces and territories. The third activity was establishing provincial forums, and during the 3-year period 15 forums that built on the activities and outcomes of the national forums were hosted. Youth Excel's fourth main activity was hosting a peer learning exchange program targeted across provinces, health and education disciplines, and research, policy and practice sectors to strengthen collaboration and learning about KDE capacity across diverse groups. Lastly, Youth Excel collaborated with experts in research, policy and practice from across Canada to develop a core set of indicators and measures for youth tobacco use, physical activity and healthy eating that could be used as part of any surveillance or monitoring tool.

\section{Methods}

Telephone interviews were conducted with Youth Excel members from provincial teams $(\mathrm{n}=7)$ and national organizations $(\mathrm{n}=2)$. Participants included 21 Youth Excel researchers ( $\mathrm{n}=12$ ), practitioners ( $\mathrm{n}=5)$ and policy makers $(\mathrm{n}=4)$ across 12 interviews. The unit of data collection and analysis was each national organization and each provincial team. Group interviews allowed for the inclusion of different perspectives from each organization and team. Over one-third $(n=8)$ of the respondents worked directly at the local or community level. Direct involvement in the design, implementation and/ or evaluation of Youth Excel was the main selection criteria for interview participants, since the purpose of the interviews was to understand assets, drivers and constraints for building KDE capacity up to the end of Youth Excel funding in November 2011. Two of the authors (KW, $\mathrm{SM}$ ) conducted the approximately onehour long interviews in November and December 2011. A 12-question, semistructured interview guide developed by Youth Excel's Evaluation Working Group guided the interviews. This interview guide was pre-circulated to allow interview participants to request input from other Youth Excel members in their jurisdiction.

Interviews were audio-recorded, transcribed and imported into NVivo 9 (QSR International, Doncaster, Vic, AU) using 3 coding passes. Each pass was structured around one of the 4 components of $\mathrm{KDE}$ capacity in an effort to understand the essential ingredients needed to build each aspect of KDE capacity.

This first pass of the analysis involved coding the text from the interviews, lineby-line, into the specific KDE component categories. This involved segmenting and labelling interview text, assigning this

FIGURE 1

Knowledge development and exchange capacity cycle

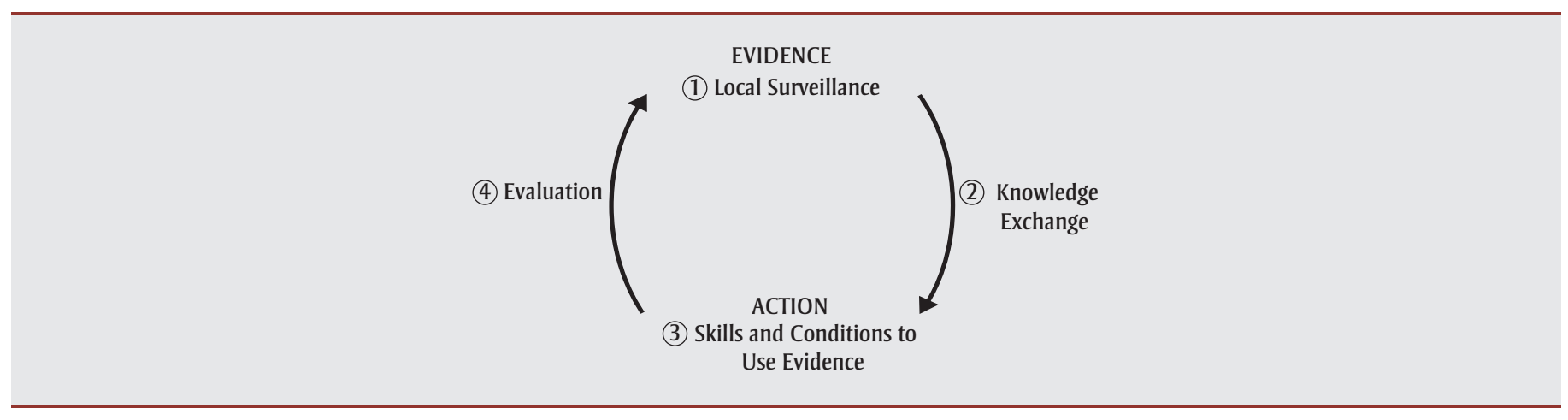


TABLE 1

Provincial and national Youth Excel members and their history of collaboration

Provincial Partners

(lead organization)

British Columbia

(University of

Victoria)

Alberta (University of Alberta)

Manitoba

(CancerCare

Manitoba)

Ontario (Public Health Ontario)

New Brunswick (University of New Brunswick)

Newfoundland and Labrador (Memorial University)

Prince Edward Island (University of Prince Edward Island)

\section{National Partners}

Pan-Canadian Joint Consortium for School Health (JCSH)

Propel Centre for Population Health Impact (Propel)

\section{Description of partner and collaboration history}

Youth Excel members in BC provide close ties between research and practice. A key player moved from government (health) to academia in 2004 and has maintained strong links through the development and evaluation of government strategies such as Action Schools! BC, a provincial initiative facilitating systemic change for healthy weights using comprehensive school health approaches and a Sugar Sweetened Beverage Education Program. Key players in BC and AB collaborate to ensure their provinces gather comparable data. Provincial leads in $\mathrm{BC}$ and $\mathrm{ON}$ collaborate on research to inform dissemination decisions.

The University of Alberta's Population Health Intervention Research Unit (PHIRU) conducts population intervention studies in AB, PE and NS. For example, PHIRU evaluates Alberta Health and Wellness's investment in healthy eating and active living with the REAL Kids survey of grade 5 students. Another collaborative project, APPLE Schools, evaluates the comprehensive school health model. EverActive Schools, a comprehensive school health initiative, also partners with Youth Excel. PHIRU and EverActive Schools also partner with government to assess other models for implementing comprehensive school health initiatives.

MB's Partners in Planning for Healthy Living (PPHL) conducts local risk factor surveillance and knowledge development and exchange for local planning with youth health as an initial focus. Founded in 2006, PPHL includes (1) all 11 MB Regional Health Authorities; (2) non-governmental organizations (Alliance for the Prevention of Chronic Disease, Canadian Cancer Society-MB Division, CancerCare Manitoba, Heart and Stroke Foundation of MB); (3) 3 government ministries (Health and Healthy Living; Education Citizenship and Youth; Healthy Child MB Office); (4) Health in Common and (5) the regional Public Health Agency of Canada (MB/SK Region). PPHL aligns mandates, priorities, investments and activities across organizations to share resources and collaborate in supporting the use of evidence to plan interventions that promote healthy living in communities across MB. MB has completed the Youth Health Survey, which facilitates activity based on local data collection.

Ontario collaborators have established numerous interconnections. They have conducted a wide range of projects, including SHAPES (see Propel description below). This provincial collaboration includes research leaders from Propel and the Ontario Ministry of Health and Long-Term Care (formerly Ministry of Health Promotion), regional public health departments and Public Health Ontario (PHO). PHO provides scientific and technical advice for those working to protect and promote the health of Ontarians. PHO builds KDE capacity via Ontario's Health Promotion Resource Centres, conducts mission-related research and evaluation and contributes evidence directly to policy and practice.

The NB Department of Wellness, Culture \& Sport, Department of Education and University of New Brunswick's Health \& Education Research Group (HERG) teamed up to work on NB's Youth Wellness strategy. Key players have worked together on tobacco control for 10 years and led the NB Anti-Tobacco Coalition (including provincial youth forums). NB partners assessed and promoted youth health in all provincial schools in 3-year cycles starting 2006/07, with follow-up support to school communities to identify priorities, community strengths and paths for action.

Through the Healthy Schools Healthy Students Initiative (HSHS), the Government of Newfoundland and Labrador supports a Comprehensive School Health approach with a cross-department (Health, Education, Recreation, Environmental Health) and a provincial HSHS committee. The provincial HSHS committee involves researchers, school health co-ordinators, policy makers and officials from the school districts and health authorities. HSHS has supported various policies and projects: implementation of district smoke-free school policies, development of School Food Guidelines, development, implementation and evaluation of Active Schools Projects in all school districts and implementation of the new physical education curriculum.

Since 2005, University of Prince Edward Island's (UPEI) School Health Research (CSHR) Group has worked with the PE Department of Education and Early Childhood Development to improve youth health. PE Education has funded 3 cycles of CSHR student data collection data in a census of PE schools using the SHAPES system (see Propel below for a description). As the focus shifts from data collection to knowledge exchange, PE partners have linked with other longstanding partners (up to 2 decades) including Canadian Cancer Society - PE Division, the PE Department of Health, the province's 3 school boards and PE schools. These groups also have connections to provincial alliances relevant to Youth Excel including the PE Tobacco Reduction Alliance, Recreation PE and the Healthy Eating Alliance.

JCSH emerged from a 2005 agreement among the provincial and territorial ministers of Health and Education and the Public Health Agency of Canada to provide leadership and build the capacity of the education and health sectors to work together to improve student health and achievement. JCSH has led an unprecedented government effort to promote collaboration within and across jurisdictions. It has undertaken a number of activities that form the basis for KDE capacity. JCSH convened data monitoring meetings with invited experts and policy makers from across Canada to advance the issues of data collection and surveillance as they relate to the overall school health agenda. With Propel it developed and tested the Healthy School Planner, an assessment tool based on the Comprehensive School Health framework, to gather evidence that guides planning and action by schools and their partners. JCSH has also proactively connected with key national organizations such as the Public Health Network and the Canadian Association of Principals to facilitate moving the agenda to ensure connection and alignment.

Propel, a collaborative enterprise, conducts research, evaluation and knowledge exchange to accelerate improvements in the health of populations. Focus areas include tobacco control, youth health, chronic disease prevention and capacity development. Propel's niche is linking evidence and action to prevent cancer and other chronic diseases. Propel works with over 200 leaders in science, policy and practice from across Canada to jointly plan, conduct and act on studies that lead to improvements in policies and programs and guide change. In addition to developing the Healthy School Planner with JCSH, Propel developed the School Health Action Planning and Evaluation System (SHAPES), an efficient means to gather student-level evidence on key health topics and feed that information back to schools and their partners. Propel is committed to moving evidence into action, in part by serving a convening role.

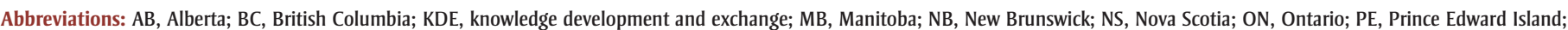
SK, Saskatchewan. 
coded text to appropriate KDE component categories and then reassigning to other categories as appropriate. After all the interviews had been coded in this way, the codes were reviewed to ensure they fit into that KDE capacity component. The second pass sorted the distilled codes into categories within each KDE component.

The third coding pass identified themes specific to each KDE capacity component. Criteria for identifying themes were based on (1) whether the majority of participants discussed the theme in relation to that KDE component and/or (2) the extent to which participants discussed that theme within or across interviews. In addition, interviews that indicated the presence of a theme (e.g. mutually beneficial partnerships, building trust, frequent dialogue, etc.) specific to a $\mathrm{KDE}$ component were continually compared with those that did not have that theme to discern whether, in fact, the theme was an essential ingredient. Finally, themes were compared and contrasted across the $4 \mathrm{KDE}$ components to identify those that were cross-cutting.

All research methods were reviewed and received ethics clearance through the Office of Research Ethics at the University of Waterloo. All the participants gave informed consent.

We enhanced confidence in our findings in several ways. The study included the lead investigator and staff from each provincial team and national organization who were most actively involved in Youth Excel. The small-group unstructured interviews (2-3 people) efficiently captured the breadth and depth of experience in each jurisdiction. To avoid introducing bias in responses, the purpose of the interviews and their timing did not conflict with any funding applications either in preparation or under review. A draft manuscript was circulated to all participants, who indicated the results resonated with their experience. Finally, an individual unaffiliated with Youth Excel conducted the analyses.

The study was purposely limited to members of Youth Excel so as to explore KDE capacity; the research perspective rather than a policy and practice perspective was more dominant among those interviewed, consistent with affiliations of Youth Excel members. Also, the experience of respondents varied across the 4 KDE components; results for the first 2 components are based on direct and indepth experience, whereas results for the third and fourth components are based on fewer experiences.

\section{Results}

Results are organized into each of the 4 KDE capacity components (see Figure 1) and into overall KDE capacity for themes that cut across 2 or more components. Results reflect participants' experiences in building KDE capacity, both before and during the 3-year Youth Excel initiative. Interview quotation perspectives are coded according to sector $(\mathrm{R}=$ research; $\mathrm{P}=$ policy; $\mathrm{Pr}=$ practice) and jurisdiction (Prov $=$ provincial; Nat $=$ national) to retain respondents' anonymity.

\section{Component 1: Local surveillance system}

Local surveillance systems collect data on stakeholder-identified priority topics considered foundational to KDE capacity, for example, youth tobacco use, physical activity, healthy eating and positive mental health.

The biggest difference now is that we have measurable data that we never had before. We had opinions. We had a little bit of national data. We couldn't walk in and have the conversations we are having with government if we didn't have the evidence, so having these provincial data for our students in our province, it helps me at a school level (R; Prov).

The following themes reflect respondents' insights on elements of a local surveillance system and how to build such systems in different jurisdictions.

\section{Mutually beneficial partnerships}

Youth Excel members underscored the importance of relationships and networks in building an effective local surveillance system (e.g. "Knowledge development and exchange is all about building relationships" [R; Prov]). Leveraging existing networks was especially important, as was building partnerships with “connectors"-individuals with links to other researchers, practitioners, policy makers-and with "negotiators"individuals who know how to seek and involve other stakeholders and who accelerate buy-in and use of complementary strengths.

Youth Excel members considered government to be a key player, though the desired role varied by jurisdiction. Some indicated that a data collection tool with a government logo or endorsement is taken more seriously than one without.

I know from my experience that if I hand out a survey that has not only a project logo but also the logos of the government of [province] on it ... it has been taken more seriously, and so I was very particular that when I started this contract with the government that I referred to that as a partnership so that I could have their logo on the survey (R; Prov).

\section{Building trust}

Establishing and maintaining local surveillance systems required building trust among players. Negotiating various perspectives across research, policy and practice and establishing shared understanding among these diverse players was complex and difficult at times. To build trust, members needed a non-judgmental environment, a willingness and ability to adapt, transparency and an enduring commitment to the vision and values established by the team.

I think that speaks to our real belief in building trust and relationships to form true partnerships and allowing enough time for that to develop (R; Prov).

\section{Frequent dialogue}

Youth Excel members considered regular and tailored face-to-face meetings with a diverse group to be essential. That such meetings included individuals from outside of the health and education sectors who recognized the added value and practical application of a surveillance system was also considered important. 
Members reported that frequent meetings facilitate "democratic conversations," both internal and external partner engagement and problem-solving of complex issues such as co-ordinating multiple existing surveys.

\section{Co-ordination of surveys}

At national, provincial and local levels, numerous surveys collect data on unique and common topics related to youth health. For best use of resources and to decrease burden on respondents and organizations, Youth Excel members noted the advantages of co-ordinating surveys at all jurisdictional levels:

...the province as a whole is in discussion around how we can, number 1 , take existing surveys and co-ordinate them, and [number] 2, fill in the gaps that aren't currently being covered particularly around childhood obesity, physical activity, healthy eating ( $R$; Prov).

They also noted the need for a deep understanding of diverse contexts and the value of bringing together the right players to accomplish this co-ordination.

\section{Core Indicators and Measures (CIM)}

Many respondents expressed the need to use consistent questions across surveillance/monitoring tools over time to facilitate meaningful comparisons between settings and populations. The most valuable features of the Youth Excel-developed CIMs were the consensus process involving research, policy and practice and their flexible use. For example, CIMs for tobacco use, physical activity and healthy eating can be used as separate modules, together and/or integrated with other questions.

Ideally, I would like to see all 3 put into surveys. It addresses what we're hearing from schools, that they're moving away from single topic interventions. As they're looking at more comprehensive strategies to tackle a number of health issues, we need a tool that can appropriately evaluate them (R; Prov).
More information on CIMs is available elsewhere. ${ }^{12}$ Adoption and the subsequent use of CIMs will take more time although doing so is essential to ensuring the usefulness of surveillance to science and practice.

\section{Component 2: Knowledge exchange}

Knowledge exchange within Youth Excel included specific products and processes that use surveillance data for planning and action and to facilitate peer learning about building KDE capacities.

Transforming data into knowledge products Data from surveillance systems needs to be transformed into information to help set clear direction in new policies and programs, evaluate existing policies and initiatives and for strategic planning purposes. The most common transformation mentioned by Youth Excel members was of data in reports. Reports at all levelsprovincial-, local- or school-level reports that provide comparative national and/or provincial-level data-are all important to their intended audience. There was particular emphasis on the value of local-level data:

People in the province realized how valuable their local data are and, in our last provincial round table, people really want that. They don't want to run even a small intervention without having data at their school levels ( $R$; Prov).

\section{The right people}

Respondents indicated that knowledge brokers-people who translate, package, interpret and communicate informationserve a valuable function especially during "knowledge exchange periods" that follow data collection periods (e.g. school years).

We were using natural knowledge brokers that were out there, healthy learners in school programs, public health nurses, community groups, and others who were in a position to bring the data forward alongside of discussions around interventions (R; Prov).

\section{Sharing and learning across sectors and jurisdictions}

Respondents emphatically supported systematic ways of learning from each other around a common purpose. They placed a high value on the national- and provinciallevel forums that Youth Excel convened. Dialogue with other jurisdictions or provinces was "inspirational" and helped Youth Excel members develop ideas and validate insights.

The round table also gave us the opportunity to connect with partners such as Aboriginal Affairs and Northern Development Canada, provinces and territories, and others working in the education sector. The round table was valuable as it stimulated thinking and encouraged partners to work together to promote comprehensive school health (P; Nat).

Relationships across the country were easier to sustain with the continuity of interactions at forums:

Knowing that there is that kind of continuity there-it builds the trust and the foundation and it enables us to pursue those linkages and assist us in our consortium endeavours or those related to [Youth Excel] CLASP on a more regular basis (P; Nat).

At least twice-yearly provincial network meetings allowed partners within each province to develop a shared agenda about KDE for youth health. These formal and informal networks created important opportunities for individuals to provide leadership, strengthen relationships and foster a helpful, non-hierarchical means of working.

Ideally, we'd have twice-yearly meetings of the provincial network. By the second provincial round table, we could see how much people valued the event. It developed a sort of hype. People were emailing me all the time saying they'd heard of the meeting, and asking to come. The invitation list doubled in size overnight. We got a 
great balance between representatives from health, education, research, policy practice-even tourism, parks and rec, and student leaders (R; Prov).

Linking provincial knowledge exchange forums with a related conference or event (e.g. healthy schools conference) helped recruit players and extend the reach of the KDE agenda.

\section{Webinars}

Webinars were a productive medium for KDE and, compared with traditional meetings, presented fewer barriers to attendance. Aside from doing away with cost and travel time, webinars could be recorded and made available for subsequent access, expanding their reach even further.

[Webinars are] a vehicle for people to get to know and look for current information about what is really going on. It's a process for people to get together and discuss and create interest and willingness to work together (R; Prov).

\section{Component 3: Skills and conditions for using evidence}

Consistent with the previous 2 components, respondents considered partnerships the most essential driver for developing the skills and conditions to use evidence. Researchers need practitioners and policy makers who value and request data to help inform intervention implementation and policy decisions. In turn, practice and policy makers need researchers to produce the relevant evidence to inform the right decisions. Researchers who can "pull up data instantly" are especially valuable as are knowledge brokers who know what data exist and can examine and understand the data and take appropriate action. Although "previously, the sectors had been working in relative isolation... there's a new ethos that says we need all sectors coming together to act on our agendas" (R; Prov).

Respondents noted the importance of a supportive environment for putting information to use, training opportunities for people to do knowledge exchange in schools and initiatives that require the use of knowledge products (e.g. school grant programs based on school-level data).

\section{Component 4: Evaluation}

Respondents acknowledged the need to evaluate-to "learn as we go"-and that the capacity to generate evidence from action is the most under-developed of the 4 KDE capacity components. The capacity to produce the most useful information hinges on appropriate evaluations being in place. A shared ideal view was that evaluations need to be embedded into the system, make optimal use of the local surveillance system and ensure timely release of findings. Evaluations would also capture a wide range of evidence, including the experience of working with innovative interventions, lessons learned and better practices among local researchers or practitioners as well as those in other jurisdictions.

\section{Overall KDE capacity}

Four themes cut across the 4 KDE components:

\section{Partnerships are key}

Leveraging existing partnerships is a hallmark of KDE capacity. The types of partnerships can vary and include university research groups, provincial government ministries and departments, public health officers and non-governmental organizations:

Another driver is the people who would link with us as a team. Relationships with the deputy and/or the minister, relationship with the school boards and the relationship with other research teams... building partnerships has been key (R; Prov).

\section{Vision and strategic leadership}

Building KDE capacity requires vision and strategic leadership. Youth Excel members expressed a need for a vision that is cocreated and maintained over time and that resonates with all partners and stakeholders involved.

\section{Language matters}

Many Youth Excel members expressed the need to find and use common language. Terms and interpretations vary widely (e.g. for comprehensive school health and in knowledge translation) despite that individuals and organizations have invested heavily in creating common terms and concepts.

One of the biggest [revelations] is communication and using common language... and although we are doing a lot of similar things, we tend to use different words or have different meanings behind the same words (R; Prov).

Thus, finding simple, common and universally understood language to communicate "building KDE capacity" is imperative.

The differences between the language and priorities of research versus policy and practice are a challenge and it takes time and effort to work through and come to common agreement (R; Prov).

\section{Funding/resources}

Respondents talked about the importance of dedicated and sustained funding for all 4 components of KDE capacity. Responses on funding sources were mixed: some considered government commitment and funding in surveillance and evaluation crucial; others noted the importance of funding from outside government to facilitate sustainability of KDE capacity (i.e. "it can better weather the storm of government changes" [R; Prov]). Respondents also acknowledged the need for and opportunities to be creative with existing resources.

What we are going to have to do is be more creative with what we have, reaching out to new partners to extend our capacity. It is about doing what we need to do more creatively (R; Prov).

\section{Discussion}

\section{Systems approach}

Results revealed new insights on building KDE capacity in Canada based on the analysis of a pan-Canadian initiative 
focused on youth aged 10 to 18 years. Five main insights are discussed.

First, the improvement cycle with $4 \mathrm{KDE}$ components may help guide capacitybuilding efforts to strengthen KDE. The provisional model was relevant across several jurisdictions and sectors and helped Youth Excel members describe and stay focused on what they were trying to accomplish, both individually and collectively.

Second, Youth Excel provides some useful examples of how to translate the conceptual model of KDE into concrete and practical actions. Youth Excel demonstrated that a foundational asset for establishing priorities for action is a system for collecting and providing feedback, in this case on youth health behaviours at the local (school, community) level. In addition there is a need to learn about innovative interventions in the field. The results of these interventions need to be documented in a way that can be easily shared and the details (both "what" and "how") in particular should be easily adapted for use under other conditions. A mechanism for routine and continuous learning also needs to be in place. Effective mechanisms include community-, provincial/territorial- and/or national-level knowledge exchange forums that convene diverse stakeholders (i.e. researchers, practitioners and policy makers) across jurisdictions. These forums provide opportunities to share experiences, form partnerships, link people/groups together and leverage stakeholders' strengths and assets. Webinars are another cost-effective way to share experiences. Evaluation is required to generate new evidence that both establishes the effectiveness of interventions and guides their improvement. Results of these evaluations need to be distilled and shared, preferably using descriptive and memorable stories that can be easily told during webinars and provincial and/or national-level forums.
Third, the Youth Excel experience suggests the need for a systems approach to building KDE capacity. Results revealed a set of interdependent factors that accelerated or constrained the development of KDE capacity. Dominant factors included a shared vision, strategic leadership, a common language, frequent dialogue, partnerships and trust-building. These factors are most closely aligned with recent developments in knowledge translation* frameworks. In health, the dominant models have evolved over the past 15 years from linear models of knowledge flow to complex models that emphasize relationships and systems. The emphasis on principles and practices of evidencebased medicine (e.g. replication of specific interventions) has shifted to a stronger focus on organizational capacity and strategies, ${ }^{12,13}$ sensitivity to context, ${ }^{14,15}$ and a learning and change process that involves multiple perspectives (including research, policy and practice). ${ }^{16-21}$ Systems models of knowledge transfer recognize that dissemination and implementation processes and relationships themselves are shaped, embedded and organized through structures that mediate the interactions among stakeholders with unique worldviews, priorities, languages, means of communication and expectations. $^{22}$ These stakeholders are tied together by a system that, in turn, is shaped by culture, structures, priorities and capacities. ${ }^{13}$ This system requires activation if its various parts are to be linked together to connect knowledge to action. ${ }^{23-25}$ This system activation may be the essence of Youth Excel.

Fourth, and consistent with a systems approach, Youth Excel offers insight into roles and relationships for partners from different jurisdictions. For example, the national organizations (JCSH and Propel) were well-positioned to efficiently support efforts within and across provinces compared with each province undertaking activities individually. Cases in point include the secretariat role served by
Propel, CIMs, national forums and the peer learning exchange program. Provincial stakeholders were most suited to supporting KDE activities within and across local jurisdictions (e.g. regional health authorities) within their provinces. For example, provincial players co-ordinated surveys, convened provincial and local-level stakeholders for action planning in their province and tailored KDE components to their context. While local players were not formal members of Youth Excel, they were instrumental in all KDE activities and it is mostly locallevel action that provincial and nationallevel organizations are enabling. The interplay across jurisdictions in Youth Excel provides some early insights into the need for a multi-level KDE system and examples of activities that can help to implement such a system.

Fifth, the Youth Excel experience shows that building KDE capacity takes time. At the end of 2011 and the 3 years of funding for Youth Excel, pan-Canadian KDE capacity for youth health was modest and highly variable across jurisdictions. Most significant developments were with local surveillance systems and related knowledge exchange, especially feedback reports for various audiences. Few developments were apparent for evaluation, and these evolved over a much longer time than the 3 years of Youth Excel; at the start of Youth Excel, some members had collaborated on various projects for as long as 16 years. Foundational assets like developing local data collection and feedback systems are complex undertakings and take a long time to develop.

\section{Conclusion}

Undertaking the future building of $\mathrm{KDE}$ capacity with a focus on youth health is both encouraging and sobering. It is encouraging that Youth Excel was able to deepen understanding of the complexities of KDE capacity and how to build it in diverse settings. Youth Excel was able to

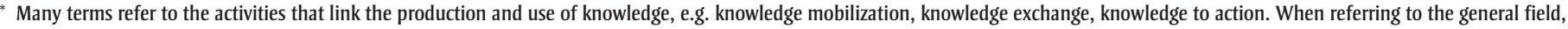
we use the expression "knowledge translation," consistent with the CIHR definition ${ }^{27}$ as "a dynamic and iterative process that includes synthesis, dissemination, exchange, and ethically sound application of knowledge to improve the health of Canadians, provide more effective health services and products and strengthen the health care system."
} 
demonstrate through experience the importance of a systems approach to $\mathrm{KDE}^{26}$ and how to translate a systems approach into assets and actions. An invaluable asset is the growing community in Canada that is committed to and acting to achieve a KDE platform that enables individual projects and interventions.

What is sobering about the future is the work that remains to be done and the corresponding commitments needed from multiple jurisdictions (local, provincial, territorial, national) and players (research, policy and practice, health and education). Earlier work in the United States (with leadership from the Society for Prevention Research) came to similar conclusions about the need for community monitoring and feedback systems and the sustainable infrastructure to support these systems. Meeting these needs in Canada and abroad will allow us to achieve Youth Excel's vision of better evidence for use and better use of evidence in the service of youth health.

\section{Acknowledgements}

Youth Excel members include Patti-Jean Naylor and Karen Strange (University of Victoria), Paul Veugelers and Kate Storey (University of Alberta), Margaret Schwartz (APPLE Schools), Jane Griffith (University of Manitoba and CancerCare Manitoba), Kate McGarry and Tannis Erikson (CancerCare Manitoba), Heather Manson, Melody Roberts and Jennifer Robertson (Public Health Ontario), Bill Morrison and Lynn Ann Duffley (University of New Brunswick), Marlien McKay (Wellness Branch, Government of New Brunswick), Donna Murnaghan and Brandi Bell (UPEI), Antony Card (Memorial University of Newfoundland and Labrador), Katherine Kelly, Susan Hornby and Jo-Ellen Craig (Joint Consortium for School Health), Steve Manske, Barbara Riley, Christina Kroeker and Katy Wong (University of Waterloo).

This research was supported by a financial contribution from Health Canada through the Canadian Partnership Against Cancer and the Canadian Cancer Society (grant \#2011-701019). The sponsors had no involvement in the study design, collection, analysis or interpretation of the data. Nor were the sponsors involved in writing of this article or in deciding to submit it for publication. The views expressed represent the views of the authors and not necessarily those of the project funder.

\section{References}

1. Baker Jr. EL, Potter MA, Jones DL, et al The public health infrastructure and our nation's health. Annu Rev Public Health. 2005;26:303-18.

2. Centers for Disease Control and Prevention. Division of Global Public Health Capacity Development: 2008 Annual Report. Atlanta (GA): U.S. Department of Health and Human Services, Centers for Disease Control and Prevention; 2009.

3. Canadian Institutes of Health Research. Building a Sustainable Public Health Research Infrastructure in Canada. Ottawa (ON): CIHR-Institute of Population and Public Health; 2003.

4. Canadian Public Health Association; Provincial and Territorial Public Health Associations. A path toward building public health capacity. Ottawa (ON): Canadian Public Health Association and Provincial and Territorial Public Health Associations; 2005.

5. Canadian Public Health Association to the House of Commons Standing Committee on Health. Enhancing the Public Health Human Resource Infrastructure in Canada. Ottawa (ON). 2010 May.

6. Canadian Institutes of Health Research. The future of public health in Canada: developing a public health system for the 21st Century. Ottawa (ON): CIHR; 2003.

7. Coalitions linking action and science for prevention (CLASP) [Internet]. Toronto (ON): Canadian Partnership Against Cancer; 2012 [cited 2012 Nov 6]. Available from: http:// www.partnershipagainstcancer.ca/priorities /2007-2012-initiatives/primary-prevention -2007-2012-strategic-initiatives/coalitions -linking-action-science-for-prevention-clasp $-2 /$
8. White House Task Force on Childhood Obesity. Solving the problem of childhood obesity within a generation: White House Task Force on Childhood Obesity Report to the President. Washington (DC): Executive Office of the President of the United States; 2010.

9. Lagarde F, LeBlanc CM, McKenna M, et al. School policy framework: implementation of the WHO global strategy on diet, physical activity and health. Geneva $(\mathrm{CH})$ : World Health Organization; 2008.

10. Riley BL, Manske S, Cameron R. Youth Excel: towards a pan-Canadian platform linking evidence and action for prevention. Cancer. 2011;117(10 Suppl):2281-8. doi: 10.1002/cncr.26046.

11. Public Health Agency of Canada. Curbing childhood obesity: a federal, provincial, territorial framework for action to promote healthy weights. Ottawa (ON): Public Health Agency of Canada; 2012.

12. Frenk J. Balancing relevance and excellence: organizational responses to link research with decision making. Soc Sci Med. 1992;35(11):1397-404.

13. Best A, Terpstra JL, Moor G, Riley B, Norman CD, Glasgow RE. Building knowledge integration systems for evidenceinformed decisions. J Health Organ Manag. 2009;23(6):627-41.

14. Green LW. From research to 'best practices' in other settings and populations. Am J Health Behav. 2001;25(3):165-78.

15. Van de Ven AH, Johnson PE. Knowledge for theory and practice. Acad Manag Rev. 2006:31(4):802-21.

16. Rychetnik L, Frommer M, Hawe P, Shiell A. Criteria for evaluating evidence on public health interventions. J Epidemiol Community Health. 2002;56(2):119-27.

17. Best A, Stokols D, Green LW, Leischow S, Holmes B, Buchholz K. An integrative framework for community partnering to translate theory into effective health promotion strategy. Am J Health Promot. 2003;18(2):168-76. 
18. Green LW. Public health asks of systems science: to advance our evidence-based practice, can you help us get more practice-based evidence? Am J Public Health. 2006;96(3):4069. doi: 10.2105/AJPH.2005.066035.

19. Glasgow RE, Emmons KM. How can we increase translation of research into practice? Types of evidence needed. Annu Rev Publ Health. 2007;28:413-33. doi: 10.1146 /annurev.publhealth.28.021406.144145.

20. Green LW, Glasgow RE, Atkins D, Stange K. Making evidence from research more relevant, useful, and actionable in policy, program planning, and practice slips 'twixt cup and lip'. Am J Prev Med. 2009;37(6 Suppl 1):S18791. doi: 10.1016/j.amepre.2009.08.017.

21. Green LW, Ottoson JM, García C, Hiatt RA. Diffusion theory and knowledge dissemination, utilization, and integration in public health. Annu Rev Publ Health. 2009; 30:151-74. doi: 10.1146/annurev.publhealth .031308 .100049 .

22. Frenk J. Balancing relevance and excellence: organizational responses to link research with decision making. Soc Sci Med. 1992;35(11):1397-404.

23. Best A, Holmes B. Systems thinking, knowledge and action: towards better models and methods. Evidence \& Policy. 2010:6(2):145-59. doi: 10.1332/174426410 X502284.

24. Best A, Hiatt RA, Norman CD; National Cancer Institute of Canada Joint Working Group on Translational Research and Knowledge Integration of the Advisory Committee for Research and the Joint Advisory Committee for Cancer Control. Knowledge integration: conceptualizing communications in cancer control systems. Patient Educ Couns. 2008;71(3):319-27. doi: 10.1016/j.pec.2008.02.013.

25. Holmes BJ, Finegood DT, Riley BL, Best A. Systems Thinking in dissemination and implementation research. Section 2. In: Brownson RC, Colditz GA, Proctor EK, ed. Dissemination and Implementation Research in Health: Translating Science to Practice. Oxford: Oxford University Press; 2012. p 175-191.
26. Public Health Agency of Canada. Curbing Childhood Obesity: A Federal, Provincial, Territorial Framework for Action to Promote Healthy Weights. Ottawa, ON: Public Health Agency of Canada. 2012.

27. Canadian Institutes of Health Research (CIHR). More about knowledge translation at CIHR [Internet]. Ottawa (ON): CIHR; 2003 [cited 2013 Dec 11]. Available from: http://www.cihr-irsc.gc.ca/e/39033.html 